\title{
Pocketbook on Regional Anesthesia Techniques: Each Line Matters
}

\author{
Habib Md Reazaul Karim ${ }^{1}$, Abhijit S. Nair ${ }^{2}$
}

Dear editor,

There has been an ardent interest noticed in the last decade amongst members of anaesthesia fraternity to learn the art of regional anaesthesia (RA). Use of ultrasound (US) has revolutionised the practice of RA all over the world. Every month there is a description of either a new block or a modification of an existing block. Although this keeps RA enthusiasts occupied with various experiments and thus reinventing his/her skills, it also adds to the confusion. The US workshops are useful to Anaesthesiologist's who have access to the US.

Practitioners in the periphery especially freelancers and Anaesthesiologists working in small, resource-limited setups are the ones who should be skillful in landmark/ loss of resistance (LOR) and peripheral nerve stimulation (PNS) guided RA techniques. Anatomy, landmarks, and techniques are equally important [1]. RA that is usually taught in medical colleges and teaching institutes to postgraduate students are spinal/epidural anaesthesia, few upper limb blocks (supraclavicular/axillary), and few lower limb blocks (femoral/sciatic/popliteal). The students do not get adequate confidence during training and later either have to attend workshops or become faculty in some teaching institutes to master RA skills.

The relationship between nerve and needle tip at the moment of injection is critical. Nerve localisation techniques have evolved over the years [2]. There are workshops conducted all over the globe that teach US and PNS-guided RA techniques. However, it has been observed that the participants are mostly not actively practicing hands-on during such sessions. An illustrated pocketbook showing images, key points, and relevant landmarks of the regularly performed RA techniques were therefore long-awaited. Finally, three RA enthusiasts from India: Dr. Santosh Kumar Sharma, Dr. Tuhin Mistry, and Dr. Kala Eshwaran have compiled a book in which they have described LOR-based and PNS-guided techniques using

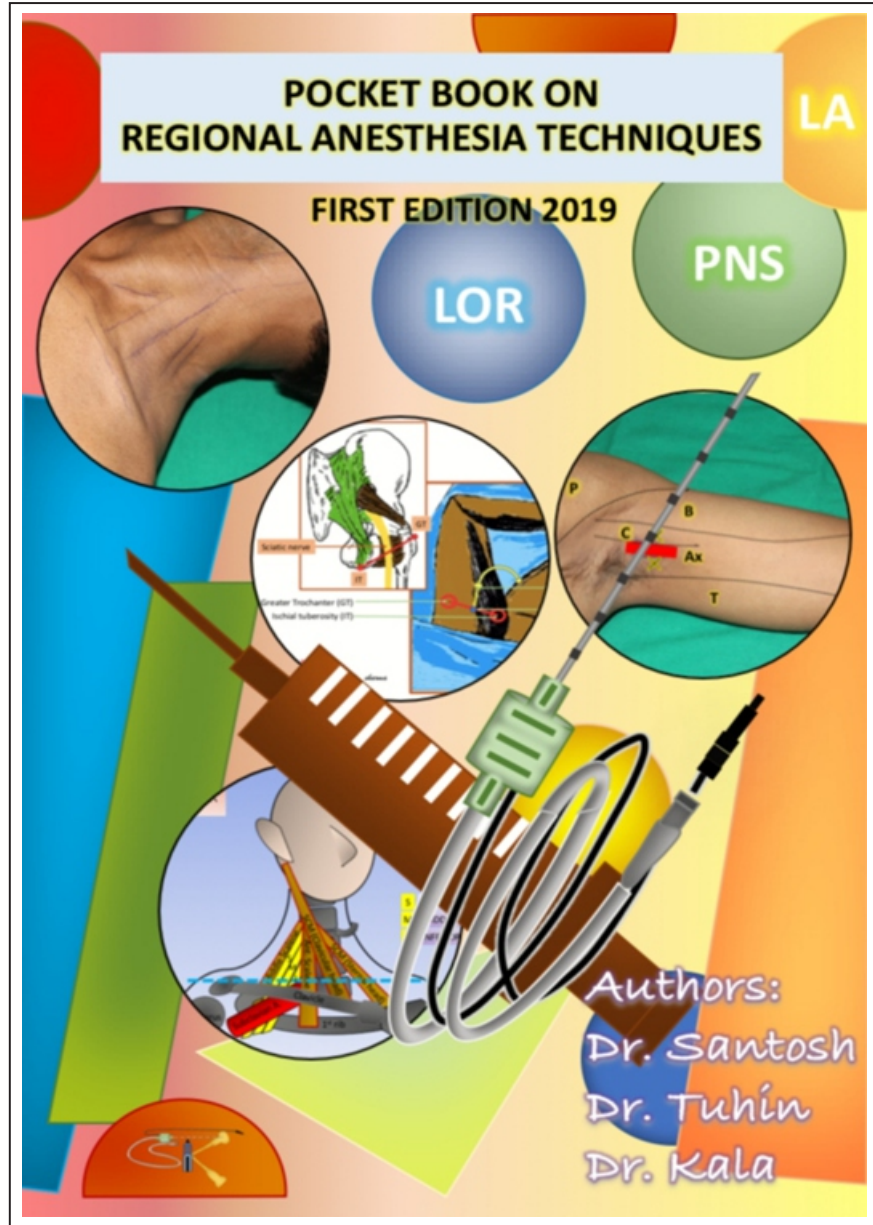

Figure 1: Figure showing the front side of the pocketbook.

illustrated and self-explanatory pictures. The book is titled 'Pocket Book on Regional Anesthesia Techniques' which is published by Pulse publications, Gorakhpur, UP, India (Figure 1). While Dr. Santosh Kumar Sharma and Dr. Tuhin Mistry are presently associated with teaching institutes, Dr. Kala Eshwaran is a free-lance Anaesthesiologist practicing in suburban Mumbai, and particularly popular for conducting high-risk cases under RA using LOR or PNS. There are 40 pages in this pocketbook which might appear less

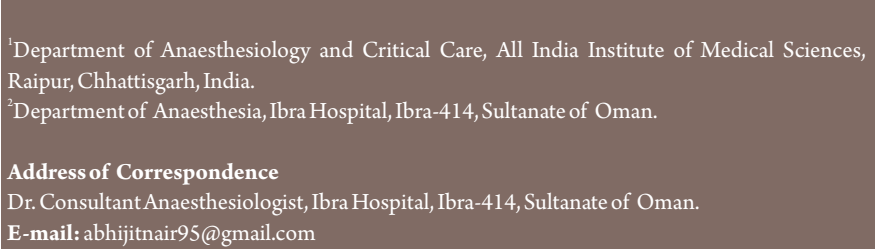

DOI: 10.13107/jaccr.2021.v07i03.190

This is an Open Access journal, and articles are distributed under the terms of the Creative Commons Attribution Non-Commercial-Share Alike 4.0 License (http://creativecommons.org/licenses/by-nc-sa/4.0) which allows others to remix, tweak, and build upon the work non-commercially as long as appropriate credit is given and the new creation are licensed under the identical terms. 
for the amount of information that could have been made available for RA techniques. However, the images and sketches in the book are very succinctly illustrated and very easy to understand. We believe this is an effort made by authors to emphasize that RA techniques are not formidable and can be understood and mastered by knowing the surface anatomy and a certain amount of practice. This is an era of the US, and authors have not touched it in this handbook, which we believe is a conscious attempt. The highlighted RA tips at the bottom of the page are an excellent, worthy addition to each technique described by the authors. The section on abdominal wall blocks is fascinating, and one realises that a sophisticated US machine is not always required for performing these blocks. The selfexplanatory images could also help students preparing for postgraduate qualifying exams in Anesthesia, and even for European Diploma in Anesthesia and Intensive Care (EDAIC) and European Diploma in Regional Anesthesia (EDRA) to understand and memorise block techniques and anatomy quickly.
In conclusion, we believe this book is a must for every RA enthusiast, especially for someone who has started practicing recently or is practicing in resource-limited centers. Incorporating RA techniques in free-lancing and small centers will not only increase one's credibility and confidence, but would also eventually transform into excellent perioperative outcomes.

We wish the authors great success and expect a bigger version with more illustrations and elaboration in the next edition. We also believe that the authors will enlist the suggested bibliography at the end of each chapter for further reading, especially for postgraduate students who also need to appear theory paper.

Declaration of patient consent: The authors certify that they have obtained all appropriate patient consent forms. In the form, the patient has given his consent for his images and other clinical information to be reported in the Journal. The patient understands that his name and initials will not be published, and due efforts will be made to conceal his identity, but anonymity cannot be guaranteed.

Conflict of interest: Nil Source of support: None

\section{References}

1. Vadhanan P, Tripaty DK, Adinarayanan S. Physiological and pharmacologic aspects of peripheral nerve blocks. J Anaesthesiol Clin Pharmacol.2015;31:384-93.
2. Helen L, O'Donnell BD, Moore E. Nerve localisation techniques for peripheral nerve block and possible future directions. Acta AnaesthesiolScand. 2015; 59:962-74.

\section{How to Cite this Article}

Karim HMR, Nair AS | Pocketbook on Regional Anesthesia Techniques: Each Line Matters | Journal of Anaesthesia and Critical Care Case Reports | September-December $2021 ; 7(3): 29-30$. 